Academic Platform Journal of Engineering and Science

\title{
Tasarımın Uzun Boyun Seramik Femoral Baş Protezinin Yüksek Kırılma Oranına Katkısının Sonlu Elemanlar Analizi ile Araştırılması
}

\author{
*Mustafa Ünal \\ Karamanoğlu Mehmetbey Üniversitesi, Karaman, Türkiye. mustafaunal@kmu.edu.tr, \\ Araştırma Makalesi \\ Geliş Tarihi: 19.06.2019 \\ Kabul Tarihi: 01.03.2020
}

$\ddot{O} z$

Üstün aşınma direncine sahip olan seramikler, genç hastaların femur başı protezi için en iyi malzeme seçeneklerindendir. Bununla birlikte, seramiklerin doğal dezavantajları kırılganlıklarıdır. Bu nedenle, seramik femur başlarının üretim ve tasarım faktörleri dikkatlice düşünülmelidir. Aksi takdirde, yüksek kırılma oranına bağlı olarak, 2001 yılında seramik femoral başların geri çağrılması olayında olduğu gibi daha ciddi bir soruna neden olabilir. Her ne kadar geri çağrılan bu seramik başların yüksek kırılma oranları, temel olarak imalat işlemindeki bir değişiklikle ilişkilendirilmiş olsa da, aynı partide üretilen uzun boyun tasarımlı seramik başların neden kısa boyun tasarımlı seramik başlara göre daha yüksek kırılma oranına sahip oldukları konusunda kesin bir tespit yapılamamış ve bu konuda bir mekanik analiz bulunmamaktadır. Bu çalışmanın amacı, tasarım faktörünün uzun boyunlu seramik femoral başlarının daha yüksek kırılma oranına olası katkısını belirlemek için sonlu elemanlar analizi kullanılarak iki farklı seramik femur başı (kısa ve uzun boyunlu seramik baş) üzerindeki gerilme dağılımının analizini yapmaktır.28 mm çapındaki iki farklı şekilde (kısa ve uzun boyunlu) tasarlanmış seramik başlar, 85 yaşındaki bir insanın yürüme koşulu altında maruz kaldığı maksimum yük altında sonlu elemanlar analizi (SEA) ile gerilme dağılımı test edildi. Katı modellemesi yapılmış femur ve protezlere önce ağ örgüsü oluşturulmuş ( 75000 düğüm ve $\sim 50000$ eleman) ve literatürden elde edilen malzeme özellikleri modele atanmıştır Solidworks simülasyonundan elde edilen SEA sonuçları, uzun boyunlu seramik başın konik-delik temas bölgesinde zaman içinde yorulma kırılmasına yol açabilecek yaklaşık 5 kat daha fazla lokal gerilme yoğunlaşmasının varlığını göstermiştir. Bu sonuç tasarım faktörünün, üretim kusurunun ötesinde uzun boyunlu seramik başların daha yüksek kırılma oranına katkıda bulunabileceğini göstermektedir. Bu nedenle, tasarım faktörleriyle alakalı olan seramik başlar üzerindeki bu tür lokal gerilme yoğunlaşma alanlarının varlığı, yeni seramik femur başlarının tasarımı ve üretimi sırasında daima dikkate alınmalıdır.

Anahtar Kelimeler: Biyomekanik, Seramik Femoral Baş, Femur, Sonlu Elemanlar Analizi, Kalça Protezi

\section{Investigation of Contribution of Design to the High Fracture Rate of Long Neck Ceramic Femoral Head Prosthesis by Finite Element Analysis}

\author{
Karamanoğlu Mehmetbey University, Karaman, Turkey. mustafaunal@kmu.edu.tr
}

\begin{abstract}
Having a superior wear resistance, ceramics have been among the best options of material for femoral head prosthesis of young patients. However, the inherent disadvantage of ceramics is their brittleness. Therefore, the production and design factors of ceramic femoral heads should be considered carefully. Otherwise, it may cause more serious problem such as in the example of recalling event of ceramic femoral heads in 2001 due to the high fracture rate. Although the high fracture rate of these recalled ceramics heads were primarily associated with an alteration in a manufacturing process, why the long neck designed ceramic heads produced in the same batch had higher fracture rate compared to short neck designed ceramic heads have not been fully identified and there have been no mechanical analysis on it. The purpose of this study was to analyze the stress distribution on two different ceramic femoral heads (short and long neck ceramic heads) using finite element analysis to identify the possible contribution of design factor to the higher fracture rate of long neck ceramic femoral heads. Two different designed ceramic heads with 28-mm diameter were analyzed by finite element analysis (FEA) in a femur under maximum walking load conditions of 85-year old person Solid modeled femurs and prostheses were first meshed ( 75000 nodes and $\sim 50000$ elements) and the
\end{abstract}


material properties obtained from the literature were assigned to the model.. The FEA results obtained from Solidworks simulation showed 5-times higher local stress concentration on long neck design which may lead to a fatigue fracture over time on the taper-bore contact area of long neck ceramic head, suggesting that design factor may also contribute to the higher fracture rate of long neck ceramic heads beyond manufacturing defect. Therefore, the presence of such local stress concentration areas on ceramic heads related to design factors should always be taken into account during the design and manufacture of the new ceramic femoral heads.

\section{Keywords: Biomechanics, Ceramic Femoral Head, Femur, Finite Element Analysis, Hip prosthesis}

\section{GİRIŞ}

İnsan vücudundaki kalça eklemi sferoid femur başı ve asetabulum boşluğu olmak üzere iki ana bölümden oluşur. Kalça eklemi yürüme, koşma ve dönme gibi çok yönlü hareketler sağlar [1]. Kalça eklemi bazen vücudun ağırlığının üç veya beş katına eşit olan döngüsel yüklemeye maruz kalır ve yaşam boyunca bu döngüsel yüklemeye dayanmalıdır [1, 2]. Osteoartrit, avasküler nekroz, artrit ve travma bazen kalça ekleminde kusurlara neden olabilir ve bu kusurlar hastalar için ağrıya sebep olarak yaşam kalitesini düşürür [3, 4]. Böyle durumlarda, kalça eklemi kalça artroplastisi denilen cerrahi prosedür vasıtasıyla bir protez ile değiştirilmelidir. Bu ameliyat total kalça artroplastisi ve yarı artroplasti olarak iki şekilde yapılabilir [5]. Total kalça arteoplastisi (TKA), hem femur başı hem de asetabulumun, ağrıyı gidermek ve yeniden yükleme işlevini yerine getirmek için uygun protezler ile cerrahi yol ile değiştirilmesi işlemdir $[5,6]$.

Total kalça protezi kabaca iki ana bölümden oluşur: femoral gövde (stem) ve asetabular bileşen (komponent). Femur içine oturan femoral gövde, baş (bilye) bileşenli metal bir şafttır. Asetabular bileşen ise temel olarak metalik kap ve plastik (ya da seramik) bir astar/yataktan oluşur [7]. Ayrıca gövde ve baş, üreticiye bağlı olarak tek parça veya modüler olarak tasarlanabilir. Protezin femoral gövde kısmının üretimindeki birincil amacı, normal kalça fonksiyonu sırasında tekrarlanan mekanik döngüsel yüklenmeye karşı yüksek direnç ve uzun süreli biyouyumluluk sağlamasıdır [6]. Bu yüzden seramiklerin ve polimerlerin özelliklerine kıyasla metallerin yüksek çekme ve yorulma dayanımı, metalleri implant taşıyan mekanik yükler için ilk tercih yapar $[8,9]$. Femoral gövde genellikle titanyum alaşımı veya kobalt kromdan üretilirken, total kalça protezinin baş ve yatak kısımları, her spesifik uygulama ve ihtiyaca göre farklı malzemeler tarafından üretilebilir [8-10]. Örnek olarak, hastanın durumuna bağlı olarak, protez metal başlık ve polietilen yatak, metal başlık ve metal yatak, seramik başlık ve polietilen yatak veya seramik başlık ve seramik yatak gibi kombinasyonlarından biri ile oluşturulabilir [4, 6, 10]. Bu farklı kompinasyonların her birinin hem avantajları hem de dezavantajları vardır [6, 9-11]. Femoral baş kısmı ile yatak arasında veya yatak-asetabular kabuk birleşiminden salınabilecek aşınma kalıntıları osteolizin bir sonucu olarak implantı kaybetmeye neden olabileceğinden dolayı [4], seramik baş üzerine polietilen yatak veya seramik baş üzerine seramik yatak düşük sürtünme sağladığı için en çok tercih edilen kombinasyonlardır [12, 13].

Özellikle, sağlamış olduğu düşük aşınma üretimi ve düşük sürtünme katsayısından dolayı [14, 15] günümüzde kalça protezlerinin femoral baş ve yatak kısımlarının önemli bir kısmı seramikten üretiliyor ve seramiklerin mükemmel malzeme özellikleri nedeniyle bu oran gün geçtikçe daha da artmaktadır $[13,15,16]$. İyonik bağlar nedeniyle seramikler yüksek mekanik ve kimyasal çözülmeye karşı direnç gösterirler; ancak, seramik malzemelerin en büyük dezavantajı kırılgan oluşlarıdır [9, 17-19]. Seramikler yüksek basma dayanımlarına sahipken, çekme ya da darbe yükleme karşısında düşük dayanıklıktadırlar [8, 9]. Literatürde, travma, cerrahi hata, çarpma, malzeme hatası, tasarım faktörü, hatalı üretim, obezite, bileşenler arasında uyumsuzluk ve küçük top çapı seramik femoral başın kırılma nedenleri arasında rapor edilmiştir [4, 20-22].

Seramiklerin doğasından gelen bu dezantajından dolayı, seramik femorol baş ve yatak üretimi ve tasarımı konusunda azami derecede dikkat edilmesi önem arz ediyor. Aksi takdirde hem üretici hem de hastalar açısından istenmeyen sonuçların ortaya çıkmasına neden olabilir. Bunun en bilinen örneklerinden bir tanesi 2001 yılında bir firma tarafından 13 farklı partide üretilmiş olan zirkonya esaslı seramik femoral başlarının yüksek kırılma oranı nedeniyle geri çağrılmasıdır [23-25]. Bu olayı daha ilginç kılan kısım ise tüm geri çağrılan seramik başların hepsinin Ocak 1998'den sonra yeni bir tünel firını kullanılarak üretilmiş olmasıydı. Bu tarihten önce farklı fırın kullanılarak üretilen seramik başların kırılma oranı sadece \% 0,009 iken [26]. Kırılma oranı, bu geri çağırılan tüm seramik başlar için \% 2,2 [23] ve özellikle TH 93038 partisinde üretilen seramik başlar içinse neredeyse 3 'te 1 oranındaydı [25, 26]. TH 93038 partisinde üretilen seramik femoral başlar, altı farklı baş-delik dizaynına sahip $28 \mathrm{~mm}$ çaplı femoral başlardan oluşuyordu [23]. Bunların arasında da en çok uzun boyun tasarımına sahip seramik başlar (Şekil 1) kırılmaya maruz kaldı [23]. Daha sonra literatürde yayınlanmış farklı karakterizasyon tekniklerine dayanan analizler sonucunda bu geri çağrılan zirkonya esaslı seramik başlarının yüksek kırılma sebebinin ana sebebinin üretim süreci değişikliği olduğu rapor edilse de [23-27], farklı tasarımlar arasında niçin uzun boyunlu tasarımın nispeten daha fazla kırılmaya maruz kaldığı hakkında deneysel ya da bilgisayarlı bir analize dayanan kesin bir sonuç rapor edilmemiştir. 

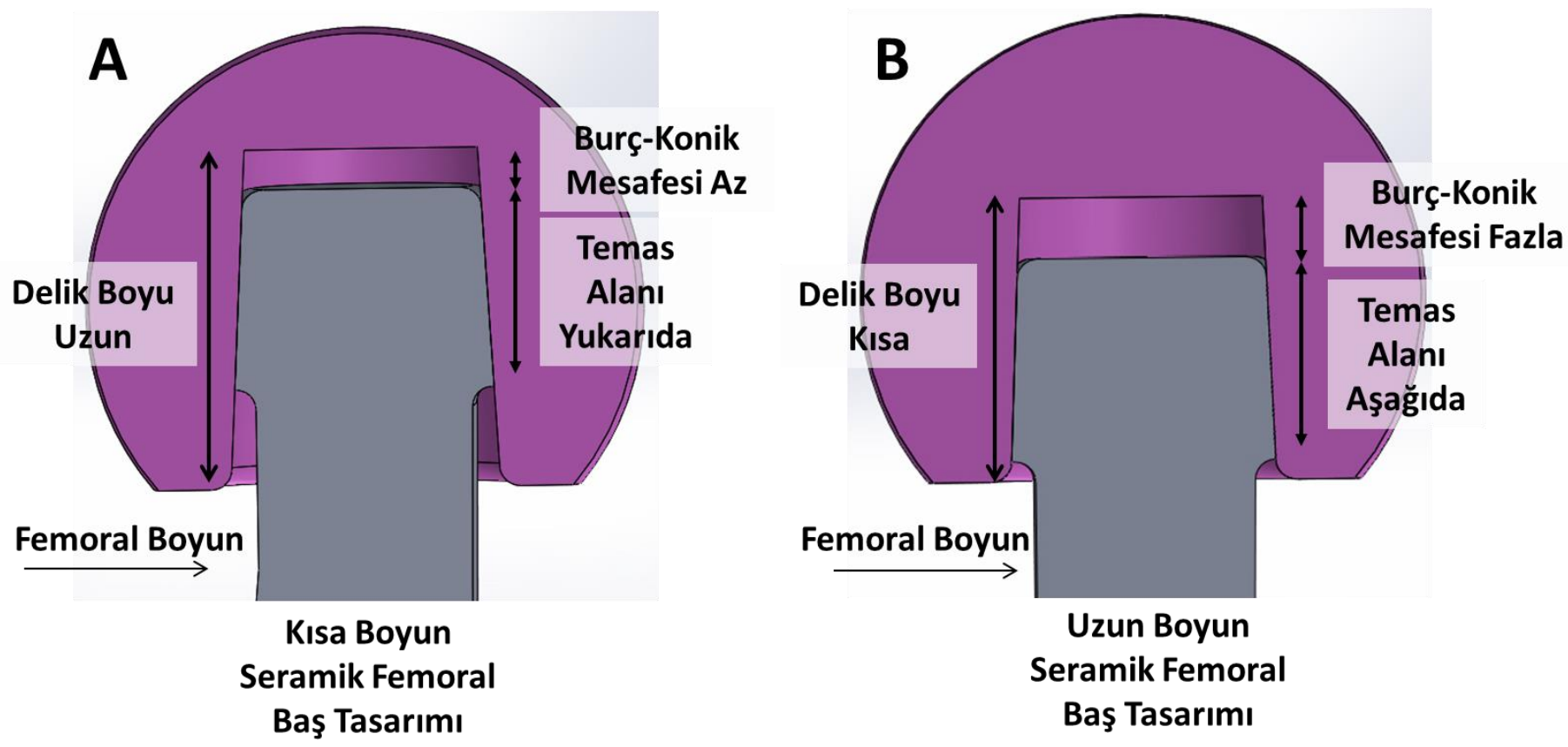

Şekil 1. A) Kısa ve B) uzun boyunlu seramik femoral başların tasarım parametreleri. Femoral başın delik boyu kısa boyun tasarımında uzun boyun tasarımına kısayla daha fazla iken, burç-konik mesafesi uzun boyun tasarımında daha fazladır. Kısa boyun tasarımında konik-baş temas alanı yukarıda bulunurken, bu temas alanı uzun boyunlu seramik başlarda aşağıda bulunur.

Sadece bir çalışmada, araştırmacılar üretimsel hata ötesinde, problemin muhtemel biyomekaniksel bir yanı olabileceğini de tartışmış ve uzun boyunlu tasarıma sahip zirkonya esaslı seramik femoral başlarda taramalı elektron mikroskopu (TEM) ile yapılan analizler sonucunda konik ve femoral baş deliğinin temas etme noktasında olağan dışı dairesel kırılma izlerine rastlayarak, sebebin tasarımdan kaynaklanan biyomekaniksel bir problem ile de alakalı olabileceğini öne sürmüşlerdir [28]. Fakat burada ki iddea deneysel yada bilgisayar destekli mekanik bir analiz ile desteklenmemiştir.

Buradan yola çıkarak, bu çalışmanın amacı sonlu elemanlar analizi ile kısa ve uzun boyunlu $28 \mathrm{~mm}$ çaplı zirkonya-esaslı seramik femoral başlara sahip kalça protezlerinin (Şekil 1), femur içinde ve normal yürüme koşulu altında gerilme analizini yaparak, bu özel durum için uzun boyun tasarımlı seramik femoral başların yüksek kırılma oranına tasarım faktörününden kaynaklanan biyomekaniksel mekanizmaların katkısı olup olmadığını mekanik bir analiz ile incelemektir."

\section{MALZEME VE YÖNTEM}

\subsection{Protezlerin ve Femurun Modellenmesi}

$\mathrm{Bu}$ çalışmada kullanılan femoral gövde ve seramik başların tasarım parametreleri "Oxinum Zirconium Femoral Heads" ve "Smith \& Nephew" kataloglarından elde edilerek Solidworks programı ile katı modelleri oluşturulmuştur. 28 mm çapında gövdeye sahip olan kısa ve uzun boyun tasarımına sahip iki adet zirkonya femoral baş katı modeli oluşturularak (Şekil 1), bu femoral başlar aynı ölçülerdeki iki adet Ti-6Al-4V malzeme özelliklerine sahip femoral gövde üzerine yerleştirilmiştir (Şekil 2).

Her iki zirkonyum seramik femoral başı da $28 \mathrm{~mm}$ olan aynı çapa sahip olmasına rağmen, bunlar arasındaki tek fark, kısa ve uzun olmak üzere iki farklı delik uzunluklarına sahip olmalarıdır (Şekil 1). Uzun boyunlu seramik baş tasarımında, temas alanı alçaktadır; bununla birlikte, kısa boyunlu tasarımında, baş ve gövde çiftinin temas alanı yüksek bir konumdadır. Ek olarak, trunnion-bore (burçkonik) mesafesi kısa boyun tasarımı için kısa, uzun boyun tasarımı için bu mesafe daha fazladır (Şekil 1).

Protezin femoral gövde kısmı titanyum alaşımlı kısa modüler femoral kalça protezi olarak modellendi (Şekil 2).
A

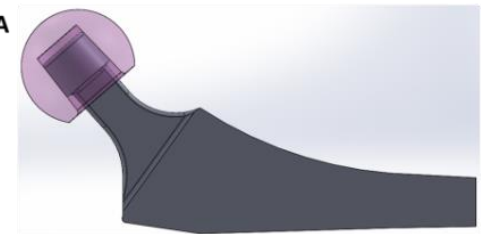

B

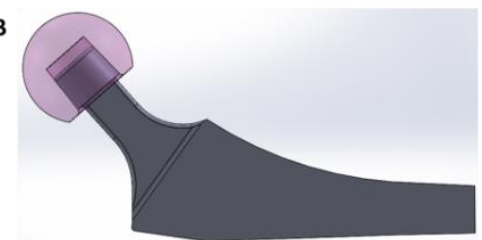

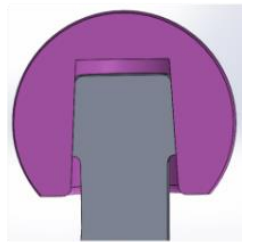

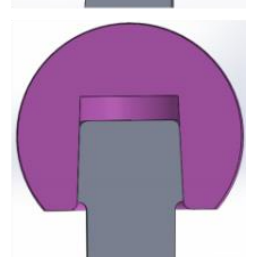

Şekil 2. A) Kısa ve B) uzun boyun tasarımına sahip seramik başların, aynı ölçülere sahip kısa modüler femoral gövdelere yerleştirildikten sonraki konumlarının gösterimi 
$\mathrm{Bu}$ çalışmada kullanılan femur (uyluk kemiği) modeli PhysiomeSpace'in halka açık arşivinden elde edilen bütün iskelet modelinden izole edilerek elde edilmiştir. 78 yaşında ortalama ağırlık ve boydaki bayan bir kadavra iskeletine ait olan bu iskelet modeli, tüm vücut bilgisayarlı tomografi (BT) taraması verileriyle modellenmiştir. PhysiomeSpace tarafindan sağlanan kadavra iskeleti modelinin. ".stl" uzantılı dosyası SolidWorks programına yüklenerek, kullanılacak olan sağ femur izole edilmiştir.

Üç boyutlu protezlerin (Şekil 2) ve sağlam bir femurun modeli oluşturulduktan sonra (Şekil 3), femur başı kesilerek, protezi yerleştirmek için femurda gerekli olan alan protezin gövde kısmının ölçülerine göre oluşturuldu (Şekil 3) ve protez tüm yüzey bölgelerinden femura bağlandı (Şekil 3-4).

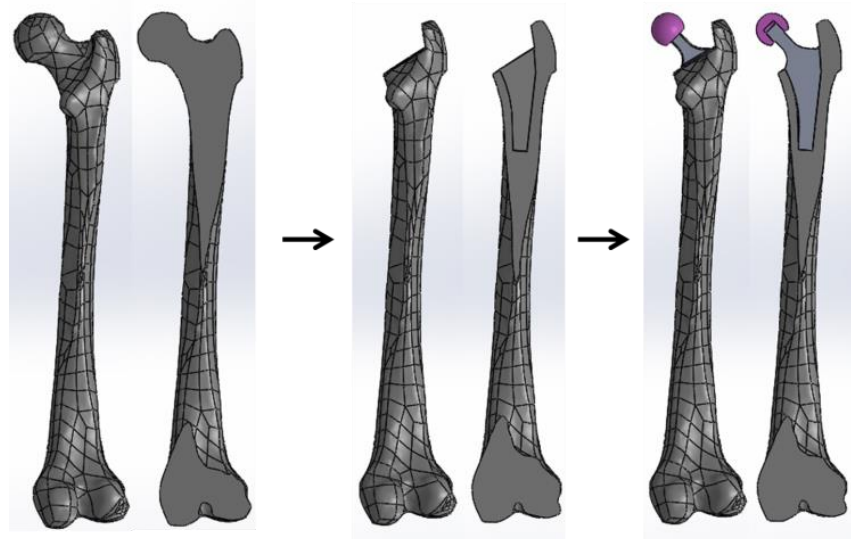

Şekil 3. Katı modellemesi yapılan kalça protezlerinin femur içine yerleştirilme basamaklarının gösterimi.
A

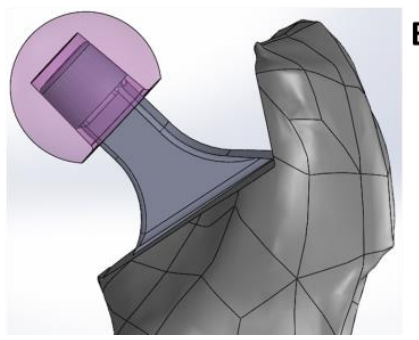



Şekil 4. A) Kısa ve B) uzun boyun tasarımına sahip seramik başlı kalça protezlerinin femur içine yerleştirildikten sonraki görünüşleri.

\subsection{Sınır ve Yükleme Koşulları}

Sonlu elemanlar analizi SolidWorks simulation yazılımı ile gerçekleştirildi. Protez yerleştirilmiş femur modelleri femur ucundan sabitlendi (Şekil 5). Kaslar, kalça temas kuvvetleri ve bağlanma noktaları yürüme esnasındaki maksimum yüke maruz kalma durumu için literatürden alındı ve analize uyarland1. Literatürde, yükleme rejiminin basitleştirilmesi için gluteus medilus, gluteus minimus ve maksimum gluteus abdüktör kuvveti ve tensör fasya lata ve vastus lateralis olarak toplandı. Tablo 1'de gösterilen bu veriler literatürde $85 \mathrm{~kg}$ insan için maksimum yükte yürürken elde edilmiş verilerdir [29, 30]. Daha sonra, kaslar ve kalça temas kuvvetleri literatürden yaklaşık olarak belirlenmiş olan P1, $\mathrm{P} 2$ ve $\mathrm{P} 3$ noktalarına etki edecek şekilde yerleştirildi $[29,30]$ (Şekil 5).

Analizin basitleştirilmesi için modellerde kullanılan tüm malzemelerin homojen ve izotropik malzeme olduğu varsayıldı ve literatürden elde edilen malzemesel özelliklerinin modellere ataması yapıldı. Femur kemiğin elastik modülü, literatürde verilen deneysel verilerden faydalınarak $17 \mathrm{GPa}$ olarak alınmıştır çünkü femur kemiğin 20-86 yaş aralığındaki elasik modülünün ortalama değeri 17 GPa olarak belirlenmiştir [31] ve yaygın olarak kemiğin sonlu elemanlar analizlerinde bu değer kullanılmaktadır (Tablo 2).

Tablo 1. $85 \mathrm{~kg}$ ağırlıktaki bir insanın yürüme esnasında femur üzerine etki eden kuvvetler ve temas noktaları [29, 30].

\begin{tabular}{|c|c|c|c|c|}
\hline \multirow{2}{*}{$\begin{array}{c}\text { Yürüme } \\
\text { esnasında }\end{array}$} & \multicolumn{2}{|c|}{$\begin{array}{c}\text { Kuvvet Bileşenlerinin } \\
\text { Büyüklükleri } \\
\text { (Vücut Ăgırlığı: } ~ 85 \mathrm{~kg} \text { ) }\end{array}$} & $\begin{array}{c}\text { Temas } \\
\text { Noktas1 }\end{array}$ \\
\cline { 2 - 5 } & $\mathrm{X}[\mathrm{N}]$ & $\mathrm{Y}[\mathrm{N}]$ & $\mathrm{Z}[\mathrm{N}]$ & \\
\hline $\begin{array}{c}\text { Kalça Temas } \\
\text { Kuvveti (F1) }\end{array}$ & 451 & 268 & -1916 & $\mathrm{P} 1$ \\
\hline $\begin{array}{c}\text { Abdüktör } \\
\text { (F2) }\end{array}$ & -485 & -36 & 723 & $\mathrm{P} 2$ \\
\hline $\begin{array}{c}\text { Tensör fascia } \\
\text { latea } \\
\text { (fasya lata), } \\
\text { proximal part } \\
\text { (F3) }\end{array}$ & -60 & -97 & 110 & $\mathrm{P} 2$ \\
\hline $\begin{array}{c}\text { Tensör fascia } \\
\text { latea } \\
\text { (fasya lata), } \\
\text { distal part } \\
\text { (F4) }\end{array}$ & 4 & 6 & -159 & $\mathrm{P} 2$ \\
\hline $\begin{array}{c}\text { Vastus } \\
\text { laterais (F5) }\end{array}$ & 8 & -155 & -777 & $\mathrm{P} 3$ \\
\hline
\end{tabular}

Tablo 2. Sonlu elemanlar analizinde kullanilan malzemelerin ve kemiğin malzemesel özellikleri [32, 33].

\begin{tabular}{|c|c|c|}
\hline Malzeme & $\begin{array}{c}\text { Elastik } \\
\text { Modülü (GPa) }\end{array}$ & $\begin{array}{c}\text { Poisson } \\
\text { Oranı }(v)\end{array}$ \\
\hline $\begin{array}{c}\text { Femur } \\
\text { (Kortikal Kemik) }\end{array}$ & 17 & 0.33 \\
\hline $\begin{array}{c}\text { Titanyum Alaşımı } \\
\text { (Ti-6Al-4V) }\end{array}$ & 110 & 0.30 \\
\hline $\begin{array}{c}\text { Zirkonya esaslı } \\
\text { seramik (Y-TZP) }\end{array}$ & 208 & 0.31 \\
\hline
\end{tabular}




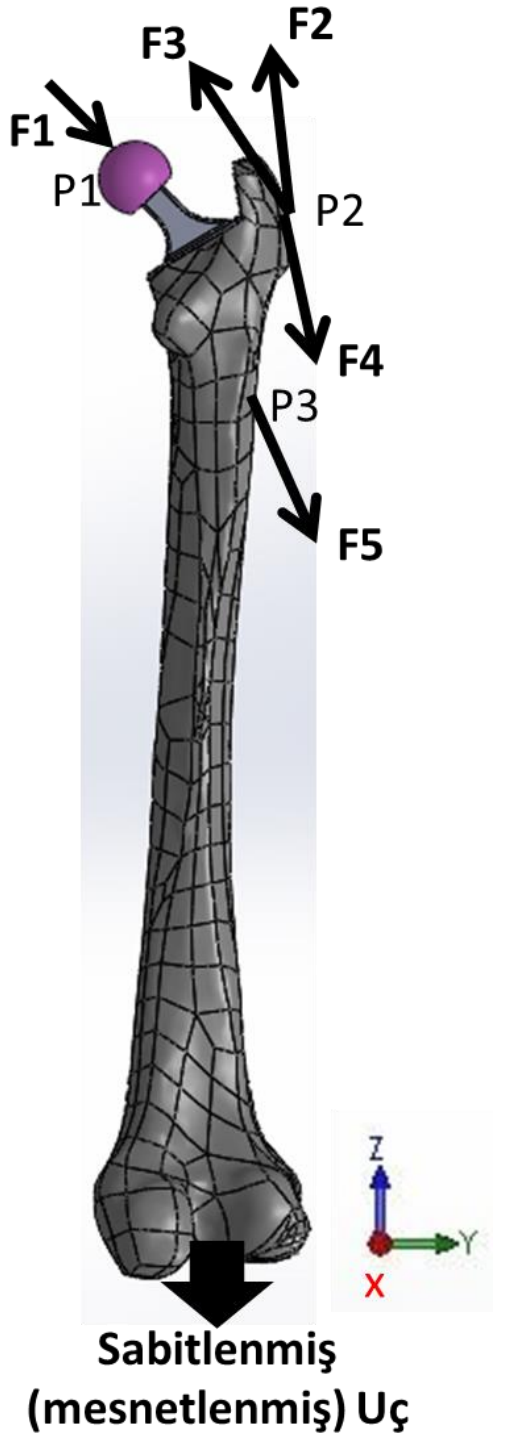

Şekil 5. Yürüme esnasında femur üzerine etki eden kuvvetlerin ve etki noktalarının gösterimi.

Daha sonra şekil 6'de gösterildiği gibi ağ (mesh) örgüsü oluşturularak, kısa boyun seramik baş tasarımlı model 69518 düğüm (node) ve 44247 elemana, uzun boyun seramik baş tasarımlı model ise 75945 düğüm (node) ve 49269 elemana ayrıldı. A ğ örgüsü oluşturulup, sınır ve yükleme koşulları belirlendikten sonra sonlu elemanlar analizi gerçekleştirildi ve von-Mises stres (gerilme) değerleri hesaplandı (Şekil 7).

\section{BULGULAR VE TARTIŞMA}

$\mathrm{Bu}$ çalışmada, tasarım faktörünün yüksek kırılma oranına sahip uzun boyun tasarımlı zirkonya esaslı seramik femoral başa etkisi olup olmadığını araştırmak için sonlu elemanlar analizi metotu ile aynı sınır ve yükleme koşulları altında iki farklı seramik baş tasarımının gerilme analizi yapıldı. Analiz sonuçları von-Mises stres dağılımı açısından sunuldu ve tartışıldı (Şekil 7).
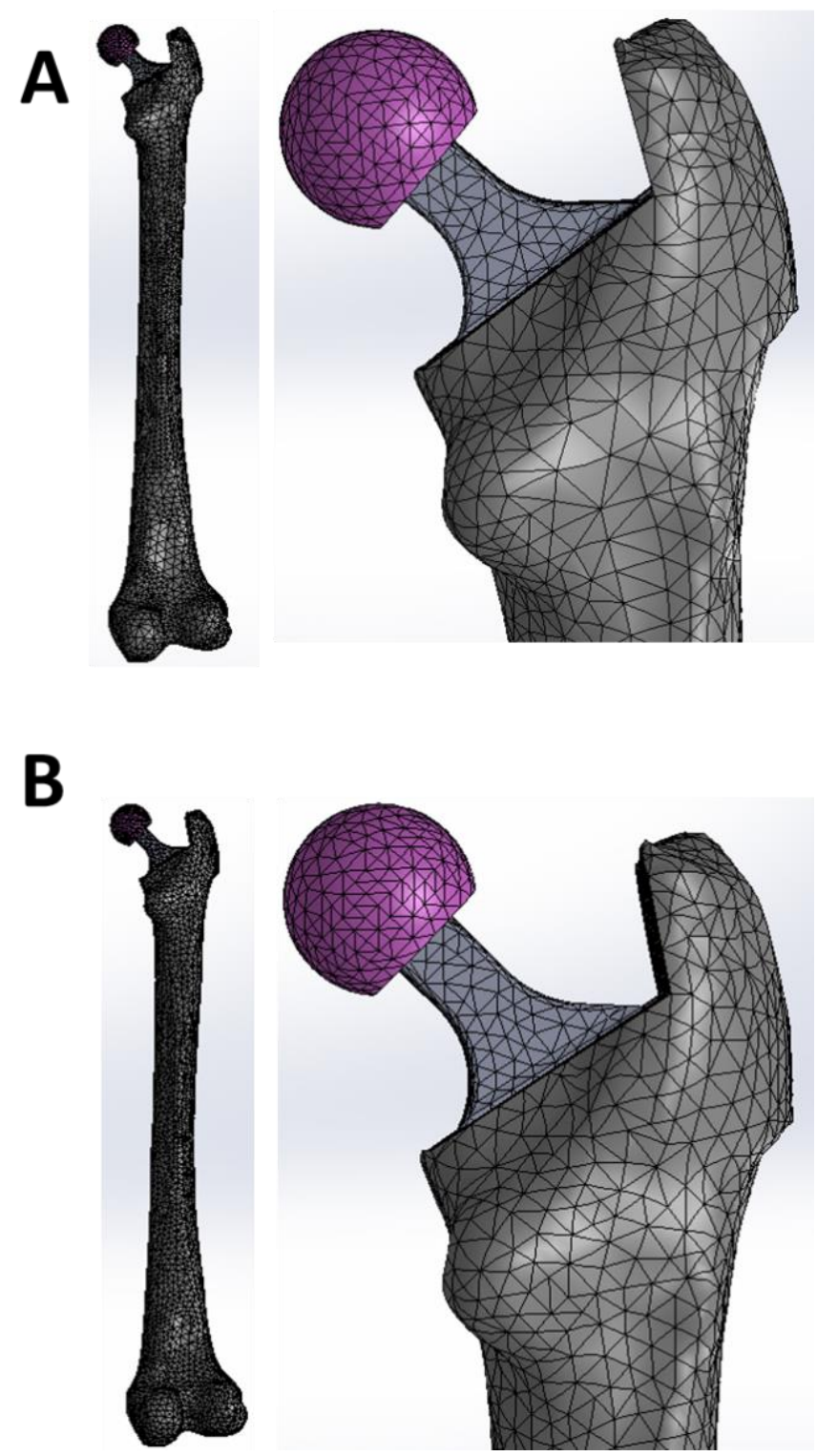

Şekil 6. Femur içerisine yerleştirilen A) Kısa ve B) uzun boyun tasarıma sahip seramik başlı kalça protezlerinin sonlu elemanlar ağ (mesh) örgüsü yapısının gösterimi.Her bir katı model yaklaşık 75000 düğüm ve 50000 elamana ayrılmıștır.

Sonlu elemalar analizi sonucunda ortaya çıkan iki tasarım arasındaki von-Mises stres dağılımı karşılaştırmasında, kısa boyun tasarımına kiyasla uzun boyunlu tasarımda gövde konik-delik ara yüzeyinde yaklaşık 5 kat daha fazla maksimum stres dağılımının bulunduğu görüldü (Şekil 8).

Bu bulguyu biyomekanik açıdan değerlendirdiğimizde, uzun boyunlu tasarımda, yürüme gibi normal yaşam aktiviteleri sırasında dahi oluşan bu yaklaşık 5 kat daha fazla değerdeki lokal stres yoğunlaşım bölgesi (kısa boyun tasarımı için ortalama $30 \mathrm{MPa}$ ve uzun boyun tasarımı için ortalama 150 $\mathrm{MPa}$ ) (Şekil 8), zaman içerisinde yorulma yüklenmesine bağlı olarak seramik baş kırılma riskini artırabilir. 


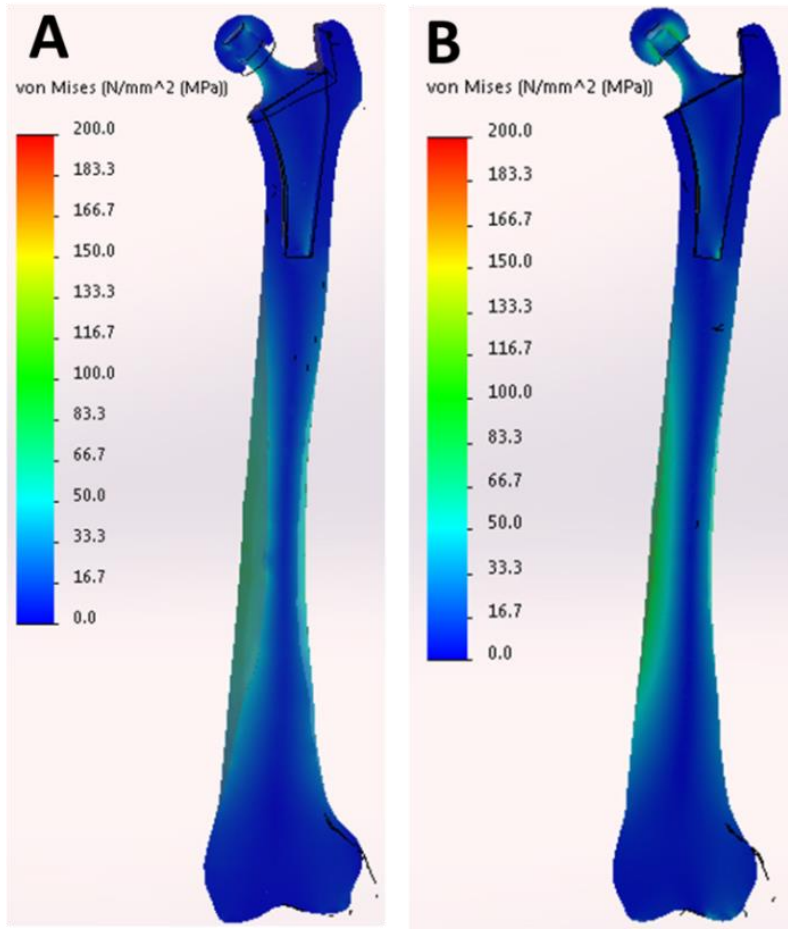

Şekil 7. İçerisine protez yerleştirilmiş femur üzerinde yürüme koşulları altında maksimum yük esnasında oluşan von-Mises stres dağılımının $0-200 \mathrm{~N} / \mathrm{mm}^{2}$ aralığındaki gösterimi. En yüksek gerilme dağılımı konik-delik temas alannda gözlemlenmiştir.

Bunun muhtemel sebebi, kısa boyun tasarımına kıyasla delik ve konik arayüzeyindeki temas alanında oluşan lokal gerilme yoğunlaşmasının uzun vadede ki yorulma yükü altında, mikro ve yüzey çatlaklarına sebep olabilme ihtimalinin yüksek olmasıdır. $\mathrm{Bu}$ açıdan, uzun boyunlu olarak tasarlanmış seramik femoral başın uzun vadede mekanik açıdan yetersizliği ve kırılma riskinin artması, zirkonya esaslı seramiklerin tasarımdan kaynaklanan konik-delik temas bölgesinde ortaya çıkan yüksek lokal stres yoğunlaşmasından (Şekil 8) kaynaklandığı söylenebilir.

Daha önce bu geri çağırma olayına sebep olan faktörlerin tartışıldığı çalışmalar da mekanik bir analiz yapılma dan bazı iddealarda bulunulmuştur. Örneğin, Masonis ve ark. [23] ve Panagiotopoulos ve ark. [28] konik ve delik arasındaki temas bölgesinden TH 93038 partisinde üretilen femoral başlar için dairesel kırılma izlerinin varlığını TEM'den elde edilen fotoğraflar ile göstermişlerdir. Panagiotopoulos ve ark. [28] zirkonya esaslı seramik femoral baş kırılmaları konusunu biyomekanik açıdan ele almış ve TEM analizleri sonucunda ortaya çıkan dairesel kırılma desenlerinden yola çıkarak, yüksek oranda kırılma yüzdesine sahip uzun boyunlu tasarıma sahip zirkonya esaslı seramik başların konik-delik temas bölgesindeki yorulma yükü ile ilişkili olabileceğini iddia ettiler. Fakat bu iddia bugüne kadar mekanik bir analiz ile desteklenmemiştir. Panagiotopoulos ve ark. [28] bu seramik femoral baş kırılma olayının, üretim hatası ötesindeki gerçek mekanizmasının problemli fiksasyon veya tasarım parametreleri ile ilgili olabileceğini düşünmüşlerdir. $\mathrm{Bu}$ çalışmada yapılan mekanik analizler bu iddiayıdestekler biçimde, konik-delik temas alanında normal yürüme esnasında oluşan maksimum yükleme koşulları altında bile lokal gerilme yoğunlaşması oluştuğunu göstererek (Şekil 7 ve 8), bu lokal gerilme yoğunlaşmasından ötürü uzun boyun tasarıma ahip zirkonya esaslı seramik femoral başların kısa boyunlu sahip zirkonya esaslı seramik femoral başların kısa boyunlu tasarımları ile karşılaştırıldığında daha fazla kırılganlığa sahip olabileceğini gösteriyor.
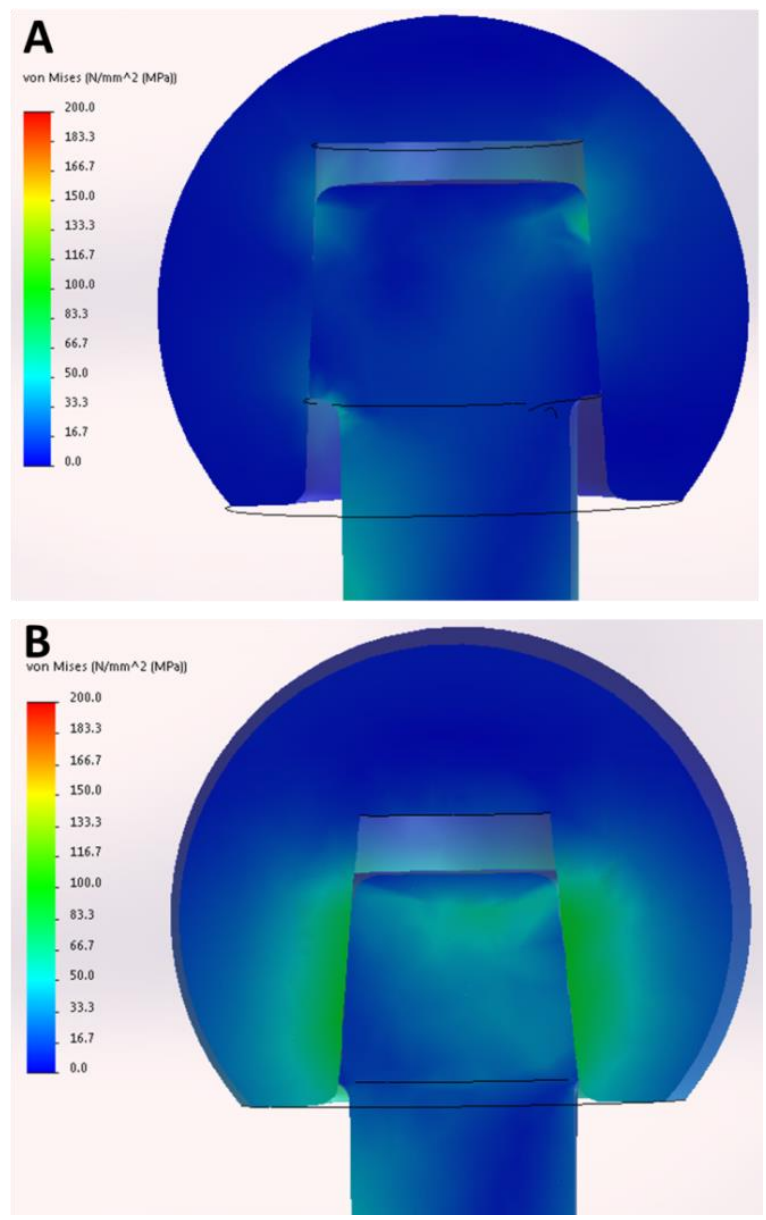

Şekil 8. Seramik başlarda oluşan von-Mises stres dağılımı. A) kısa boyun tasarımına kıyasla B) uzun tasarıma sahip seramik femoral başda konik-delik temas alanında yaklaşık 5 kat daha fazla von-Mises stres yoğunlaşması gözlemlenmiştir. ( Maksimum gerilme kısa boyun tasarımli femoral başda $30 \mathrm{MPa}$ iken bu değer uzun boyun tasarımına sahip femoral başda $150 \mathrm{MPa}$ 'dır).

Yine biyomekanik açıdan kısa ve uzun boyun tasarımlı seramik femoral başları göz önüne aldığımızda, uzun boyunlu tasarımlarda konik-delik temas alanının (Şekil 1) ve çevresel stresin (Şekil 8) delik içerisinde mekanik olarak daha zayıf bir nokta olan deliğin girişine yakın bir alanda olduğunu (Şekil 1 ve 2) ve bunun neticesinde de daha yüksek yükler altında deliğin üst kısmının köşe noktalarındaki çekme gerilmesinin kısa boyun tasarımlı femoral başa göre çok daha fazla olacağ 
vadede üretiminden kaynaklanan zayıf malzemesel özelikler ile birleşerek protezin erken kaybına sebep olabilir.

Bu çalşmanın da bazı sınırlılıkları mevcuttur. Bu çalışmada sonu elemanlar metotu ile yapılan analiz, $85 \mathrm{~kg}$ ağırlığındaki insan için maksimum yükte yürürken elde edilmiş kuvvet verilerinin statik olarak literatürde verilen ortalama mekanik özelliğe sahip kemik katı modeli içine yerleştirilen zirkonyaesaslı seramik femoral başlara sahip kalça protezlerine uygulanması ile yapıldı. Farklı dinamik yükleme koşulları altında (yürüme, koşma ve merdiven çıkma gibi), farklı özellikteki kemik yapıları ve protezler kullanılarak yapılacak olan gelecekte ki çalışmalar bu problemin daha çeşitli koşullar altında incelenmesini sağlayarak bu çalışmanın bulgularını daha da geliştirecektir.

\section{SONUÇ}

Her iki tasarım için sonlu elemanlar analizi, uzun boyunlu femoral seramik başın konik-delik arayüz temas noktasındaki lokal stres yoğunlaşmasının, uzun boyunlu tasarımın kısa boyunlu tasarıma kıyasla yüksek kırılma oranına katkıda bulunabileceğini göstermektedir. Bu tasarım faktörü bu yüksek kırılma oranının salt sebebi olmasa da, üretim kusurlarının ötesindeki protezin başarısızlık mekanizmasına katkıda bulunabileceği gözlenmiştir. Daha önce farklı kalça protezleri üzerinde yapılan deneysel ve bilgisayar-destekli mekanik analizler de, mevcut uzun boyun tasarımlı protezlerin, kısa boyun tasarımlı protezlere göre mekanik açıdan problem ortaya çıkarabileceğini belirtmektedir [35, 36]. Bu çalışma da önceki çalışmaları destekleyerek, imal kusurlarının yanında tasarım faktörlerinin de mevcut protezlerin uzun süre kusursuz şekilde kullanılması açısından önem arz ettiğini vurgulamaktadır. Bu nedenle, gerek üretici gerekse hasta açısından ortaya çıkabilecek ciddi sorunları göz önüne alarak, olası erken protez kayıplarını önlemek için protezlerin üretim ve tasarım faktörleri azami derecede dikkatlice düşünülmeli ve bu protezlerin farklı fizyolojik koşullar altında biyomekaniksel testleri yapılmalıdır. Özellikle, yeni seramik femoral baş tasarımları ve üretiminde, tasarıma bağlı olarak seramik başların erken kayıplarına neden olabilecek lokal stres yoğunlaşmasının ortaya çıkabileceği gerçeği herzaman göz önünde bulundurulmalıdır.

\section{KAYNAKÇA}

[1] S. E. Hohler, "Minimally invasive total hip arthroplasty," AORN journal, vol. 79, pp. 1243-1258, 2004. [2] X.-W. Liu, Y. Zi, L.-B. Xiang, and Y. Wang, "Total hip arthroplasty: areview of advances, advantages and limitations," International journal of clinical and experimental medicine, vol. 8, p. 27, 2015.

[3] O. Ethgen, O. Bruyere, F. Richy, C. Dardennes, and J.-Y. Reginster, "Health-related quality of life in total hip and total knee arthroplasty: a qualitative and systematic review of the literature," JBJS, vol. 86, pp. 963-974, 2004.
[4] R. Pivec, A. J. Johnson, S. C. Mears, and M. A. Mont, "Hip arthroplasty," The Lancet, vol. 380, pp. 17681777, 2012.

[5] S. Petis, J. L. Howard, B. L. Lanting, and E. M. Vasarhelyi, "Surgical approach in primary total hip arthroplasty: anatomy, technique and clinical outcomes," Canadian Journal of Surgery, vol. 58, p. 128, 2015.

[6] I. D. Learmonth, C. Young, and C. Rorabeck, "The operation of the century: total hip replacement," The Lancet, vol. 370, pp. 1508-1519, 2007.

[7] G. von Lewinski and T. Floerkemeier, "Challenges in Total Hip Arthroplasty," in Biomedical Technology, ed: Springer, 2018, pp. 295-312.

[8] N. R. Patel and P. P. Gohil, "A review on biomaterials: scope, applications \& human anatomy significance," International Journal of Emerging Technology and Advanced Engineering, vol. 2, pp. 91-101, 2012.

[9] M. Navarro, A. Michiardi, O. Castano, and J. Planell, "Biomaterials in orthopaedics," Journal of the royal society interface, vol. 5, pp. 1137-1158, 2008.

[10] M. Merola and S. Affatato, "Materials for Hip Prostheses: A Review of Wear and Loading Considerations," Materials, vol. 12, p. 495, 2019.

[11] L. Zagra and E. Gallazzi, "Bearing surfaces in primary total hip arthroplasty," EFORT open reviews, vol. 3, pp. 217-224, 2018.

[12] L. A. Beaupre, A. Al-Houkail, and D. W. C. Johnston, "A randomized trial comparing ceramic-onceramic bearing vs ceramic-on-crossfire-polyethylene bearing surfaces in total hip arthroplasty," J Arthroplasty, vol. 31, pp. 1240-1245, 2016.

[13] J. A. D'antonio and K. Sutton, "Ceramic materials as bearing surfaces for total hip arthroplasty," JAAOSJournal of the American Academy of Orthopaedic Surgeons, vol. 17, pp. 63-68, 2009.

[14] B. E. Bierbaum, J. Nairus, D. Kuesis, J. C. Morrison, and D. Ward, "Ceramic-on-ceramic bearings in total hip arthroplasty," Clinical Orthopaedics and Related Research ${ }^{\circledR}$, vol. 405, pp. 158-163, 2002.

[15] B. McEntire, B. S. Bal, M. Rahaman, J. Chevalier, and G. Pezzotti, "Ceramics and ceramic coatings in orthopaedics," Journal of the European Ceramic Society, vol. 35, pp. 4327-4369, 2015.

[16] J. Jeffers and W. Walter, "Ceramic-on-ceramic bearings in hip arthroplasty: state of the art and the future," J Bone Joint Surg Br, vol. 94, pp. 735-745, 2012.

[17] Y.-S. Park, S.-K. Hwang, W.-S. Choy, Y.-S. Kim, Y.-W. Moon, and S.-J. Lim, "Ceramic failure after total hip arthroplasty with an alumina-on-alumina bearing," JBJS, vol. 88, pp. 780-787, 2006.

[18] J. Rosneck, A. Klika, and W. Barsoum, "A rare complication of ceramic-on-ceramic bearings in total hip arthroplasty," J Arthroplasty, vol. 23, pp. 311-313, 2008.

[19] B. Habermann, W. Ewald, M. Rauschmann, L. Zichner, and A. Kurth, "Fracture of ceramic heads in total hip replacement," Archives of orthopaedic and trauma surgery, vol. 126, p. 464, 2006. 
[20] Y. D. Levy and W. L. Walter, "Complications of Ceramic-on-Ceramic Bearings: Fracture, Stripe Wear, and Squeaking," in Complications after Primary Total Hip Arthroplasty, ed: Springer, 2017, pp. 137-150.

[21] R. Rambani, D. M. Kepecs, T. J. Mäkinen, O. A. Safir, A. E. Gross, and P. R. Kuzyk, "Revision total hip arthroplasty for fractured ceramic bearings: a review of best practices for revision cases," J Arthroplasty, vol. 32, pp. 1959-1964, 2017.

[22] F. Traina, M. De Fine, A. Di Martino, and C. Faldini, "Fracture of ceramic bearing surfaces following total hip replacement: a systematic review," BioMed research international, vol. 2013, 2013.

[23] J. L. Masonis, R. B. Bourne, M. D. Ries, R. W. McCalden, A. Salehi, and D. C. Kelman, "Zirconia femoral head fractures: a clinical and retrieval analysis," $J$ Arthroplasty, vol. 19, pp. 898-905, 2004.

[24] J. Chevalier, "What future for zirconia as a biomaterial?," Biomaterials, vol. 27, pp. 535-543, 2006.

[25] G. Maccauro, C. Piconi, W. Burger, L. Pilloni, E. De Santis, F. Muratori, and I. Learmonth, "Fracture of a YTZP ceramic femoral head: analysis of a fault," J Bone Joint Surg Br, vol. 86, pp. 1192-1196, 2004.

[26] I. Clarke, M. Manaka, D. Green, P. Williams, G. Pezzotti, Y.-H. Kim, M. Ries, N. Sugano, L. Sedel, and C. Delauney, "Current status of zirconia used in total hip implants," JBJS, vol. 85, pp. 73-84, 2003.

[27] C. Piconi, G. Maccauro, L. Pilloni, W. Burger, F. Muratori, and H. Richter, "On the fracture of a zirconia ball head," Journal of Materials Science: Materials in Medicine, vol. 17, pp. 289-300, 2006.

[28] E. C. Panagiotopoulos, A. G. Kallivokas, I. Koulioumpas, and D. E. Mouzakis, "Early failure of a zirconia femoral head prosthesis: fracture or fatigue?,"
Clinical Biomechanics, vol. 22, pp. 856-860, 2007.

[29] M. Heller, G. Bergmann, J.-P. Kassi, L. Claes, N. Haas, and G. Duda, "Determination of muscle loading at the hip joint for use in pre-clinical testing," J Biomech, vol. 38, pp. 1155-1163, 2005.

[30] B.-A. Behrens, C. Wirth, H. Windhagen, I. Nolte, A. Meyer-Lindenberg, and A. Bouguecha, "Numerical investigations of stress shielding in total hip prostheses," Proceedings of the Institution of Mechanical Engineers, Part H: Journal of Engineering in Medicine, vol. 222, pp. 593600, 2008.

[31] D. T. Reilly, A. H. Burstein, and V. H. Frankel, "The elastic modulus for bone," J Biomech, vol. 7, pp. 271275, 1974.

[32] A. H. Abdullah, M. MohdAsri, M. S. Alias, and G. Tardan, "Finite element analysis of cemented Hip arthroplasty: influence of stem tapers," in Proceedings of the international Multi Conference of engineering and computer scientists, 2010.

[33] M. Borba, M. D. de Araújo, E. de Lima, H. N. Yoshimura, P. F. Cesar, J. A. Griggs, and Á. Della Bona, "Flexural strength and failure modes of layered ceramic structures," Dental Materials, vol. 27, pp. 1259-1266, 2011. [34] C. Piconi and G. Maccauro, "Zirconia as a ceramic biomaterial," Biomaterials, vol. 20, pp. 1-25, 1999.

[35] K.-H. Koo, Y.-C. Ha, W. H. Jung, S.-R. Kim, J. J. Yoo, and H. J. Kim, "Isolated fracture of the ceramic head after third-generation alumina-on-alumina total hip arthroplasty," JBJS, vol. 90, pp. 329-336, 2008.

[36] B. R. Burroughs, B. Hallstrom, G. J. Golladay, D. Hoeffel, and W. H. Harris, "Range of motion and stability in total hip arthroplasty with 28-, 32-, 38-, and 44-mm femoral head sizes: an in vitro study," J Arthroplasty, vol. 20, pp. 1119, 2005. 